\title{
CULTIVATING CRAFT IN CONTEXT: GRADUATE STUDENTS AS DIGITAL PRESERVATION CONSULTANTS FOR SMALL CULTURAL HERITAGE ORGANIZATIONS
}

\section{Trevor Owens*}

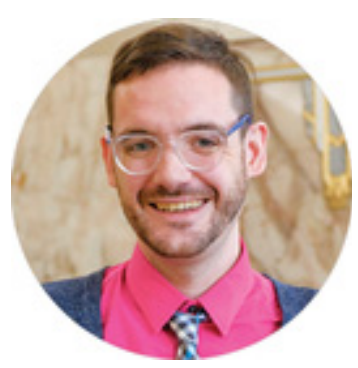

University of Maryland, 4561 Longfellow St., Hyattsville, MD, USA

${ }^{*}$ Address all correspondence to: Trevor Owens, The University of Maryland, 4561 Longfellow St., Hyattsville, MD, E-mail: trevor.johnowens@gmail.com

\begin{abstract}
Digital preservation is a craft, and craft is best honed and developed by working through issues in real world contexts. The course is now structured around a semester-long project where each graduate student acts as a digital preservation consultant for a staff member at a small cultural heritage organization. The redesigned course blends face-to-face and online activities mediated through a public course blog. In this essay, I articulate my reasoning for this approach and discuss some of the resulting impacts and outcomes of choosing this approach for teaching digital preservation. The results suggest potential broad implications for simultaneously supporting continuing education for professionals in the field through project-based learning opportunities for graduate students.
\end{abstract}

KEY WORDS: digital preservation, information science, libraries, archives, museums, blogging

\section{INTRODUCTION}

Ensuring long-term access to digital information is a substantive challenge for cultural heritage organizations of all shapes and sizes. It is also an evolving topic, which is challenging to teach. Doing digital preservation work well is increasingly understood as 
making the best use of available resources to mitigate risk of digital loss (Phillips et al., 2013). As a result, talking about digital preservation in the abstract is largely irrelevant to the critical work of managing tradeoffs between different options within the real resource constraints of an organization.

Digital preservation is a craft, and craft is best honed and developed by working through issues in real world contexts (Owens, 2018). For these reasons, I have recently reoriented the design of the University of Maryland's digital preservation graduate seminar. The course is now structured around a semester-long project, where each graduate student acts as a digital preservation consultant for a staff member at a small cultural heritage organization. I made these changes to better prepare students for work as digital preservation practitioners in cultural heritage organizations. The redesigned course blends face-to-face and online activities mediated through a public course blog. In this essay, I articulate my reasoning for this approach and discuss some of the resulting impacts and outcomes of choosing this approach for teaching digital preservation.

The base-level issues and concerns in digital preservation are not particularly complex or challenging (Chudnov, 2008). With that noted, only recently has digital preservation developed as a field and slowly become a core part of library and archives formal education programs (Hank et al., 2015; Allard et al., 2016). As a result, most of the professional workforce of libraries, archives, and museums has not been formally trained in digital preservation practices. In this context, open access online education and training materials have become critical resources supporting digital preservation continuing education (Gallinger, 2017). The redesigned digital preservation seminar allows students to develop their own understanding of digital preservation through work as consultants in service projects. This approach results in staff at participating organizations also learning from the graduate student consultants. The use of an open course blog and open access course readings allow staff from those organizations to follow along and engage with the course materials as well. While the course meets face to face, the students contribute synthesis of course readings and share their digital preservation consultant project work openly online. This effectively broadens the circle of learners participating in the course to include the staff at these organizations.

In the first year of using this approach, my students worked with organizations as diverse as the DC Punk Archive, Milwaukee Public Library, Litchfield Historical Society, Laurel Historical Society, Bostwick House, Maryland Public Television, 18th Street Singers, North Dakota State Library, and Virginia Department of Historic Resources Archives and Library. Notably, many of these organizations were at a distance from the students participating in the course. As the instructor, I observed how these collaborations generated vital discourse among the students and staff at participating organizations about digital 
preservation issues. The hands-on work as consultants also provided the students with tangible and documented work for their portfolios. It also delivered value to participating organizations through opportunities to learn and advance their practice.

I believe this approach illustrates a core concept advanced as part of my previous work developing the National Digital Platform framework for the Institute of Museum and Library Services, Washington DC (Owens et al., 2018). Namely, direct partnerships between formal education organizations and cultural heritage organizations can be beneficial to both students and staff members. The real world resource constraints of institutions provide an essential context for students to develop an understanding of the challenges of implementing digital preservation programs. At the same time, the staff members at cultural heritage institutions working with student consultants get access to both practical suggestions for their own work and open online resources they can use for their own learning. In what follows, I describe the structure and design of the digital preservation consultant project and explore some of the outcomes and results of this approach.

\section{STRUCTURE OF THE COURSE AND ORGANIZATIONAL ENGAGEMENT}

The bulk of the digital preservation seminar course work is designed around the digital preservation consultant project. Before the semester, I worked to identify organizations interested in working with student consultants. Along with this, many of the students already had ideas for organizations that they would like to work with. The primary need is to quickly establish partnerships between students and staff at organizations to make the best use of the time in the semester. In this section I describe the five components of the digital preservation consultant project.

\subsection{Establishing Partnerships with Small Cultural Heritage Organizations}

The first key part of the project is establishing the partnership with the cultural heritage organization. Using potential points of contact I have provided, or their own connections to organizations, students make contact and establish this initial relationship. I have worked to make sure that the assignments are structured in such a way that it is easy for both the student learners and the staff members they work with collaborate at a distance.

For the project to work, the following three aspects are essential for engagement from the organizations:

1. A staff member from an organization is interested in collaborating;

2. The organization has digital content it needs to manage for the long term; and 
3. The organization's digital content issues should not be so overly complex that it is difficult for a student to make a meaningful contribution to his/her work in a semester.

\subsection{Institutional Digital Preservation Survey and Report}

Once this partnership between the student and a staff member at the organization is established, each student consultant conducts interviews with one or two staff members to get a handle on their digital collections and practices. In some cases this happens face to face, or over the phone, and in other cases it occurs through email exchanges. Students' work is directly anchored in the National Digital Stewardship Alliance (NDSA) Levels of Digital Preservation, an overall framework for approaching technical aspects of the subject (Phillips et al., 2013). As a starting point, I provide students the following five broad areas of questioning to explore in interviews:

1. What is the scope of the organization's digital holdings?

2. How is the organization's digital content currently being managed?

3. What perceptions do staff members at the organization have of the state of their digital content?

4. What kinds of digital content would the organization like to acquire in the future?

5. What resources does the organization have to address digital preservation issues?

Students then write up the results of their interviews, share a draft of the results with their organization, and then publish the results as a post on the public course blog. The post provides context about the organization, its digital holdings, and its goals and desires related to digital preservation. From there, the post works through presenting an accurate and coherent report of the themes and issues that came through in interviews. At this point students are primarily interested in accurately representing the state of their organization's digital content. Before publishing this, the students must present it to their organization for feedback to make sure they are accurately describing the state of the organization's content. Making the results of this work public on the course blog allows for both students and staff from the organizations to view and engage with reports on all participating organizations.

\subsection{Institutional Digital Preservation Next Steps Preservation Plan}

With the results of the survey presented, it is now possible for students to propose key next steps for improving how the organization manages its digital content. Students post their next steps plans to the course blog (1200-3000 words). After a brief introduction on the organization and its collections, students review and assess the organization's current 
work with digital content using each area of the NDSA Levels of Digital Preservation. This allows students to identify next steps the organization could take to improve their rating on the NDSA Levels of Digital Preservation with varying levels of resource commitments. Again, before publishing this, students are encouraged to present their proposed next steps to their organization for review and input.

\subsection{Draft a Digital Preservation Policy for the Organization}

With the recommendations established, students then turn to a final key area of digital preservation work. Students draft digital preservation policies and practices for the organization. Drawing on example digital preservation policies from the course readings, students draft a short policy document for their institution tuned to the particular context and needs of the organization.

\subsection{Synthesizing Results and Lessons Learned and Producing an Executive Summary}

After doing this work, presenting it, and getting feedback from their organization, students review what worked and did not work for the project. The final deliverable is building a full copy of a consultant report that brings together each of the posts they produced for the project. They produce a cover page and one-page executive summary for their work and then append the rest of the documents to it to produce a final report. Students publish these final reports along with a blog post (500-1000 words) reflecting on what they learned from the project. This final piece of the project results in a useful piece of work that students can keep for their portfolio to show future employers the kind of work they can do to support an organization in advancing its digital preservation capability.

\section{INDICATIONS OF IMPACT}

Overall, I have been generally impressed by the quality of student work produced through this course and project design. In this section I briefly describe the perspectives of the students and staff members from participating organizations on the value of this approach.

\subsection{Students Value Real World Experience}

Numerical scores for student evaluations of the course were meaningfully higher than averages for courses across the College of Information Studies at the University of Maryland. On a 0-4 point scale from strongly disagree to strongly agree the course received an average of 3.71 on the statement "The course was intellectually challenging" and a 3.86 on "I learned a lot from this course." The average for both of those questions for courses across the college is 3.07 . 
Open-ended responses in evaluations referenced the value of the digital consultant project as a key factor for student satisfaction with the course. Multiple students specifically appreciated how the course gave them "real world experience." One student further reflecting on this point explained: "I felt that I was treated as a professional and expected to perform accordingly, a challenge that I very much appreciated." In this case, taking on the role of expert consultant pushed the student to do his/her best work. Doing the work in the open and sharing the results publicly similarly adds to this aspect of the real world nature of the work (Owens, 2012). By making the course work contribute to an organization mission students engaged with the course content in a particularly significant and meaningful way.

\subsection{Results and Impacts for Organizations}

Since teaching the course, I have heard back from a range of staff members at participating organizations on the value the course provided them. As a result, for future iterations of the course, I plan to be more systematic in collecting feedback from staff members at participating organizations. With that noted, the non-systematic responses received from organizations suggest the considerable potential value this kind of learning experience can provide in supporting capacity building for participating organizations.

Delving into one of these responses from staff members that participated in this course illustrates the potential value this type of project can provide; "Because of our participation in this course, we have concrete steps forward as we work to develop guidelines and implement good digital preservation practice. The open nature of your course and associated materials has allowed our staff to develop their own subject knowledge and continue research." The student's work was valuable to the organization. Indeed, as noted in a conversation with the staff in the organization, participating in the project resulted in the staff members being able to raise the profile of issues relating to digital preservation in their organization. Beyond that, the open online design of the course enabled the staff at the organization to learn in parallel and as co-participants in the course. In this case, staff members at the organization expressed direct appreciation for the fact that the public course blog meant that the syllabus and open access course readings were accessible to support their own learning.

In this case, not only did the students learn and establish a professional network connection with a staff member at a cultural heritage organization, they also significantly and directly resulted in enabling both that organization and the organization's staff to learn as well. 


\section{TAKING THIS MODEL FORWARD}

What I find most exciting and rewarding about the model of learning in this project is that there is significant alignment between the learning opportunity provided by the cultural heritage organizations and the optimal context for learning to become an effective and reflective digital preservation practitioner.

Many of the organizations that students worked with have only one or two full-time staff members and meager budgets. It is unlikely that these organizations would be able to afford consulting on how to improve management of their digital collections. By engaging with these organizations as consultants, students cultivate the craft of digital preservation in the real world constraints of an organization. At the same time, staff members at those organizations are offered an invitation into the community of learners in the course.

In this context, the online environment of the course blog and open access course readings create a particularly rich space for anchoring this broadened learning community. Students use the course readings and resources to develop plans for the organizations, and all of that content they learned from is simultaneously openly available to staff members in those organizations.

Unlike roles in many applied learning contexts, like internships, both the students and the staff members participate in these experiences as learners. That is, wherein an intern learns from an experienced practitioner in a context, in this case, the student becomes a peer and as a consultant takes on a form of teaching role to the practitioners working in the institutions.

Beyond this, from student responses both in person and in reviews, it is clear that this kind of "real world" work is something they find engaging and rewarding. It is also something that enables them to produce a tangible work product they can take forward as part of their portfolio when applying for jobs at cultural heritage organizations. As technologies continue to advance and needs for further continuous professional learning become more and more central to work in a range of professions, the results of this approach can illustrate for graduate education offerings to simultaneously support continuing education for professionals in the field.

\section{REFERENCES}

Allard, S., Lee, C., McGovern, N.Y., and Bishop, A. (2016), The Open Data Imperative: How the Cultural Heritage Community Can Address the Federal Mandate (No. 171), Washington, DC: Council on Library and Information Resources.

Chudnov, D. (2008), The Emperor's New Repository, Comput. Libraries, vol. 28, no. 9, pp. $39-41$. 
Gallinger, M. (2017), Open Digital Preservation Training and Professional Development Opportunities, Washington DC: Institute of Museum and Library Services.

Hank, C., Shireman, K., Lasley, N., Zhu, X., and Kirkpatrick, C.N. (2015), What We Teach: An Assessment of Graduate-Level Digital Curation Syllabi, IPRES, 2 pp.

Owens, T. (2012), The Public Course Blog: The Required Reading We Write Ourselves for the Course That Never Ends, in M.K. Gold, Ed., Debates in the Digital Humanities, Minneapolis, MN: University of Minnesota Press.

Owens, T. (2018), The Theory and Craft of Digital Preservation, Baltimore: Johns Hopkins University Press.

Owens, T., Sands, A.E., Mayeaux, S., Reynolds, E., Neal, J., and Marx, M. (2018), Digital Infrastructures that Embody Library Principles: The IMLS National Digital Platform as a Framework for Digital Library Tools and Services, in Applying Library Values to Emerging Technology, Chicago, IL: Association of College and Research Libraries, pp. 74-88.

Phillips, M., Bailey, J., Goethals, A., and Owens, T. (2013), The NDSA Levels of Digital Preservation: An Explanation and Uses, IS\&T Archiving, Washington. 